\title{
Tuad Yaita Thabo: People's Beliefs in Thungwang Subdistrict, Muang District, Songkhla Province
}

\author{
Kuntalee Vaitayavanich ${ }^{1} \&$ Sujitra Jorajit ${ }^{2}$ \\ ${ }^{1}$ Faculty of Liberal Arts, Prince of Songkla University, Hat Yai, Songkhla, Thailand \\ ${ }^{2}$ Graduate School, Hat Yai University, Songkhla, Thailand \\ Correspondence: Kuntalee Vaitayavanich, Faculty of Liberal Arts, Prince of Songkla University, Hat Yai 90110, \\ Songkhla, Thailand. E-mail: Kuntalee.v@psu.ac.th
}

\author{
Received: September 17, 2013 Accepted: November 15, 2013 Online Published: December 29, 2013 \\ doi:10.5539/ass.v10n2p221 \\ URL: http://dx.doi.org/10.5539/ass.v10n2p221
}

\begin{abstract}
Tuad Yaita Thabo has been believed in as a sacred entity in the community of Thabo, Thungwang Subdistrict. Formerly, it was a small stucco sculpture, one foot high, located outdoors near a community well. The sacredness of Tuad Yaita Thabo has been formed through a folktale about a holy spirit housed in the figure and any disrespect to this entity was prohibited. It is believed that violation of this prohibition might cause sickness and suffering; however, respect for such a sacred entity could bring contentment as desired. For instance, some community members who encountered life difficulties visited this place to ask for assistance and support and made a pledge to make a votive offering after their life difficulties were solved, raising the reputation of its sacredness within the community. Then, a small pavilion was built to house the sculpture and a religious ritual has been held annually to worship it. The processes of forming the sacredness of Tuad Yaita Thabo have been passed within the community from generation to generation through oral tradition. This revealed the process of creating beliefs in a holy spirit as a unique identity of Thai southerners. Currently, such beliefs as there is in Tuad Yaita Thabo still play important roles as a central moral support, spiritual comfort, and empowerment to community members constantly facing difficulties. Such beliefs also bring about the community unity in order to live in harmony.
\end{abstract}

Keyword: beliefs, Songkhla, Tuad Yaita Thabo

\section{Introduction}

Songkhla, a province along the eastern coast of southern Thailand, is located in between $6^{\circ} 14^{\prime}$ to $7^{\circ} 56^{\prime}$ North latitude and $100^{\circ}$ to $101^{\circ} 07^{\prime}$ East longitude (Songmuang \& Thiangdham, 1999). This province has enjoyed a long history with existing evidence of cultural beliefs in Brahmanism and Buddhism. This has been supported by many cultural objects and sites discovered in the area, such as Lingams (a Hindu phallic symbol of creative power), caves as places of worship, Buddha images and Mahayana Buddhist deities (Srisuchat, 1999). Moreover, traditional beliefs in spirits have been observed in forms of existing folktales, worshiped figures, and buildings which house sacred sculptures as well as in the form of sacred rites. Although the majority of the local residents are Theravada Buddhists, these traditional beliefs in sacred objects, spirits, deities and sacred rites rooted in Brahmanism, and Hinduism have blended into their Buddhist life patterns as witnessed in their ways of daily life.

Among these traditional beliefs held by southern Thais, there appears a belief in Tuads, which refers to sacred entities including trees, such as the Pipal trees, Banyan trees, or animals such as snakes, crocodiles, tigers, and elephants. These sacred figures may include stones or heart wood, in the belief that they house spirits who could give protection and blessings, both physical and spiritual. It is also believed that these sacred figures could save life from danger or could bring luck in business with an increase in sales. Tuads represent spirits with highly supernatural powers. It is believed that these spirits bring prosperity if revered and/or sufferings if disrespected. Tuads can be seen in many forms. Some are believed to be half-animal/half-deity such as Tuad-Ngu (snakes), or Tuad-Chang (elephants). Some may appear in the human form such as Tuad-Hum, as revered by residents in the area of Hua Khao Daeng in Songkhla Province.

Thungwang Subdistrict is located in Muang District of Songkhla. It is assumed that the area was formerly 
resided by a Muslim named Wang, who escaped from the battle after a Pattani Ruler attacked Songkhla City but unsuccessfully. He and his companions then escaped and settled down there. Later, others, both Muslims and Buddhists, moved in. Currently, many Muslims are living in Villages No. 9 and 8, adjacent to the communities belonging to Buddhists who have faith in both Buddhism and Tuads, but the latter, they believe, could save them, shelter them, and provide them with happiness and blessings. People in communities normally revere Tuads or sacred objects by giving respect, making offerings, worshiping, or performing annual religious rituals.

After the data collection during the fieldwork at Village No. 8, Thungwang Subdistrict, Muang Songkhla District, the authors found that some local residents, when driving a car or riding a motorcycle past a shrine housing the small stucco sculpture, would honk their horns. Some would perform $a$ 'Wai', pressing their palms together to show respect. The authors also witnessed some evidence of making offerings such as soft drinks, colorful fabrics, and garlands to Tuads. The interview with local residents nearby revealed that an annual religious ritual to pay tribute to Tuads has been performed for over 50 years (Rattaya, interviewed on January 4, 2011).

According to the abovementioned, it is interesting to explore further how the cultural processes of such beliefs have come about, how these cultural beliefs have been preserved for over 50 years, and what the roles of these beliefs are in the communities, in order to understand how life can be peaceful amid cultural and religious differences within communities.

\section{Objective}

To look into the process of creating belief in Tuad Yaita Thabo in Thungwang Subdistrict, Muang District, Songkhla Province and why such beliefs exist in the community.

\section{Methodology}

The researcher employed in-depth interviews to collect data and conducted analytical description. The details are described as follows.

\subsection{The Research Site}

The researcher selected the area of Thungwang Subdistrict, Muang District, Songkhla Province, as the research site for this study.

\subsection{Key Informants}

Seven key informants for this qualitative study were selected purposively with the following criteria: those who were male or female, having been living or earning their living around the ritual sites, having shared knowledge or experience of the rituals and beliefs, or those who performed or participated in rituals with direct experience of any ritual performance.

\subsection{The Theoretical Framework for Data Analysis}

Mauss's (1967) Exchange Theory explains that an exchange is considered as a commitment to receipt and return by repaying back. Such exchange is considered as intimacy and friendship. It could be said that such conduct reaffirms the bonds of individuals and groups, functioning the heart of the political system as well as providing the authority and social control.

The notions in Four Functions of Folklore which include legends, proverbs, taboos, riddles, songs, beliefs, and customs, all together can function as a means of shaping and maintaining social norms to keep order and harmony (Bascom, 1965).

The ideas of rituals and religious beliefs, as Brown (1965) explained, suggested that rituals serve as a cultural tool which signifies underlying beliefs in different matters. Ritual performance potentially impacts on community changes. As such, people attempted to manage superstitious beliefs with rituals which exercise social control for maintaining community peace and harmony (Tylor, 1958). This is in line with Durkheim (1938) who proposed a theory of religion. According to Durkheim, a religion is composed of two systems: religious practices and religious beliefs, both being unified. For him, all religions share a common aspect; that is all have profane and sacred beliefs, which represent religious practices with different levels and manners (Howells, 1962). As such, it is unfeasible to isolate religious from superstitious practices in a religious practice performed by people in different communities since both religions and superstitions are originally rooted in the same foundation which is human response to their emotional and psychological needs when they are in the tension situations (Malinowski, 1954). Human worships to symbolic entities which may include sites, objects, trees, or animals are attached to supernatural phenomena beyond their ordinary life which are hard to be understood (Geertz, 1966). The above theories contribute to an understanding of human being that faiths and beliefs have influenced community togetherness, existence, and preservation. 


\subsection{Data Collection}

Data were collected from records of historical narratives told by community members in the research site, and also written records from Cultural Office of Songkhla Province in relation to traditions and ritual practices.

The researchers conducted the fieldwork with the following methods.

1) In-depth-interviews were conducted with key informants with questions in relation to sacredness, narratives, rituals, and any building formation related to Tuad during the last 50 years.

2) The researchers also carried out participant observation. That is, the researchers attended an annual community merit making festive which was aimed at showing respect to Tuad. The researchers also employed non-participant observation by observing superstitious practices when people passed by Sala Tuad or Tuad shrine. The researchers also observed ritual practices performed by ritual performers and those participants.

\subsection{Data Analysis}

The data gathered from the records as well as from the fieldwork were analyzed by grouping, interpreting, and theming based on the content analysis of participant observation and non-participant observation, interviews, and literature reviews. Then, the researcher grouped, interpreted and coded the data to uncover conclusion of findings. All findings were presented through analytical description.

\section{Terminologies}

Beliefs refers to the acceptance of and behaviors toward existence of an entity, visible or invisible, held in Village No. 8, Thungwang Subdistrict, Muang District, Songkhla Province, as transformed into cultural behaviors shaped by such beliefs.

Tuads refers to sacred entities which local residents worship.

Cultural capital refers to values gained from the beliefs in sacred entities which are hailed as giving moral support

\section{Research Significance}

This study contributed to the understanding of cultural beliefs which are believed to result in harmony within communities as well as defining social behaviors.

\section{Results and Discussion}

\subsection{Residents in Thungwang Community: Historical Context before the Emergence of Tuad Beliefs}

Seventy years ago, Thungwang Community was a distant and undeveloped area despite its location in Muang Songkhla District. Most Buddhist residents were subsistence rice farmers and were also fruit farmers producing bananas, papayas, mangosteens, and aromatic coconuts as well as betel trees which were widely grown. The subdistrict in which this community is situated then has been given the motto up until the present time, saying, "Ban Thungwang: the city of betel for marriage, aromatic coconuts, wisdom with harmony, and the locality of decent persons". Unlike Buddhists, Muslims in this community earned their living by being fishermen along the coast.

Most Buddhist residents believed that trees, stones, and large animals were sacred and these were called 'Tuads'. They also believed in Tuad Yaita Thabo, henceforth called 'Tuad'. Originally, the Tuad was a small stucco sculpture made from the cement left from constructing a community well, placed about two meters from the community well. The sculpture was 30-45 centimeters high and 30 centimeters wide. Thon, an old resident, aged 82 , who could still recall the event, narrated that local residents have worshiped this sculpture by making offerings of some food to make a pledge or to make a votive offering (Rattaya, interviewd on January 4, 2011). This is consistent with the narration made by Praphit and Chiang, both claiming that the well water was used for bathing and also for household consumption. They said whenever people took a bath with the well water, they would take the water to pour onto Tuad first, believing that it would reduce the heat in Tuad as it was standing outdoors (Chaithong, interviewd on August 1, 2011; Nokkaew, interviewd on March 6, 2011). Some asked for help when they were in a difficult situation, such as having an illness, by expressing their grief before Tuad. Some asked for good fortune and some evidence of votive offerings to Tuad were witnessed nearby such as hats, umbrellas, drinking water, food in banana-leaf containers to show that this had been fulfilled (Sriyom, interviewd on March 6, 2011). Moreover, some residents regularly came to Tuad to clean and tidy the area; they gathered again at the area annually to hold religious offerings to Tuad. 


\subsection{Roles of Magical Folktales: The Process of Creating Beliefs in the Sacredness of Tuad}

Fifty years later, when development has been undertaken in the community by adopting The National Economic and Social Development Plan which focuses on industrial production, the community environment has changed from paddy fields to rubber plantations. The betel gardens are now insignificant, remaining only a symbol of the subdistrict. Muslims in this community were fishermen along the coast.

Today, two Buddhist temples remain in the area of Village No. 8, Thungwang Subdistrict. Residents who revere Buddhist monks usually go to the temples to make merit. While being Buddhists, they also believe in Tuad or other sacred entities in spite of entering the modern era and changing. Some residents are now government officers, and have been educated in the schooling system. The area has been developed, has a modern infrastructure and facilities including roads, electricity, water supply, and rapid communication. However, their faith in Buddhist monks, temples, and also Tuad has never faded away. Their beliefs in this sacred entity have been preserved as has been the cultural life of the community. Tuad gives them moral support. For example, some who have fighting bulls ask Tuad for victory before the fighting event takes place. Others ask Tuad for success in getting a job when taking an examination for job recruitment, while some students worship it to ask to pass examinations successfully. Some ask for lucky numbers to win the lottery, and some have won huge prizes (Sriyom, interviewd on March 6, 2011).

Folktales about Tuad are also linked to supernatural powers. According to a narration by Thon Rattaya, "There was a Thai Muslim family. Parents asked their young son to dry rice outdoors and keep an eye on any chickens that wanted to eat their rice. The son then dried the rice near Tuad. He naughtily hit the Tuad sculpture, playfully commanding it to watch his rice while he was playing around. At dusk, the son came back home with injuries in similar places to where he had hit Tuad. When his parents found out from him what had happened, they rushed to Tuad to ask for forgiveness by lighting candles and joss sticks. Surprisingly, all the wounds suddenly healed" (Rattaya, interviewd on January 4, 2011). Another story was narrated about a Thai Muslim boy cutting the grass near Tuad for his cows and he stepped over the sculpture. He insulted this statue by calling it a baby monkey. Later in the evening, the boy had stomachache and did not recover from this peculiar illness. His father then asked him about what he had done. After he told his father about what had happened, his father brought him to ask for forgiveness from Tuad by lighting candles and joss sticks. After returning home, he suddenly recovered from his stomachache. This narration is also consistent with that told by Nai Sriyom (interviewd on March 6, 2011). The folktales about Tuad's supernatural powers were also extended to how Tuad could solve life difficulties for many locals. Some asked for recovery from illness and then, surprisingly, they got well. Some asked for success in their job application and they were offered jobs after that (Petcharat \& Changthong, interviewd on August 1, 2011). When many got blessings from Tuad, its reputation spread widely and people talked about its sacredness. Even though the locals stopped consuming water from the well, some evidence of using it for blessings and support still remains in the community.

Moreover, the folktales about the beliefs in Tuad's sacredness have been narrated in the form of dreams. Wai Chainui, for example, said, "One night, I dreamed that Tuad was unwell due to standing in the open air" (Chainui, interviewd on January 4, 2011). After getting up, he told the dream to his close companions in the community and then they decided to build a small pavilion covering the sculpture in order to protect it from rain and sunlight. The community members cooperated well on the construction. They believed that Tuad could unite the community members and serve as moral support, and who could give blessings by easing their life difficulties and also giving them fortunes that they wished for. This small construction has emphasized the strong beliefs in Tuad among community residents. Today, although a dream can be explained by human consciousness in terms of scientific knowledge, a dream, in terms of spiritual state, could be a form of human belief in the supernatural. As the ancient Greeks and Romans believed, a dream was a message from gods. Chinese people believe that a dream could lead to their ancestors who have passed away (Wikipedia, 2011). As for Thais, a dream is a form of spiritual journey (Misap, 2011), being an omen for the future or a mystical communication channel between spirits and human beings. A dream then can be a means of legitimating the sacredness of Tuad among the community members, as no one could deny.

\subsection{Rituals of Faith: A Bond of Membership among the Community Residents}

Five years ago, a group of the residents in the community agreed that the area where Tuad was located should be renovated. That is, formerly, the Tuad sculpture was placed on the ground in the open air but then it was lifted up into the small pavilion or shrine by the community members who also donated construction items such as bricks, stones, sand, and roof tiles. Some devoted their energy to cutting grass. Some Muslims donated wood for construction and also helped construct the building. To relocate Tuad to the building, the residents carefully and 
respectfully carried out the activities by holding a religious ritual. It entailed offering a prayer as in a Brahmin rite, using holy thread to merge the residents' souls into Tuad. Buddhist monks were also invited to chant and sprinkle holy water on those who participated (Chainui, interviewd on January 4, 2011). Today, the area where Tuad is housed looks respectful.

In the community of Thungwang, an annual religious ritual of making merit to Tuad is held by inviting Buddhist monks to chant, to sprinkle holy water, to give blessings and to have a lunch given by local residents. The residents gather at the compound where Tuad is located to eat together the food brought in large pots, while some Muslims bring some fresh seafood to join the ceremony as well. In the afternoon, there is a ceremony of sprinkling holy water onto a Buddha image, pouring water on the hands of their elders and also on the Tuad sculpture. In the evening, there is a festive event in which a local leader may hire a group of entertainers to perform a shadow play, and to perform Nora (a southern Thai traditional dance) and/or have a singing contest, all to entertain the community residents. The event is held yearly on 12 April.

Thai Muslims in the community are religious. There are two mosques in Village No. 9. Both Buddhists and Muslims in the community are cooperative, helping each other when they have a religious rite by supporting or giving things to each other. This reflects a beautiful attitude of unity within the community.

The above cultural phenomena indicates a cultural capital (values gained from the beliefs in sacred entities which are hailed as giving moral support) within the community, resulting from the accumulation and integration of cultural diversity of different beliefs such as Theravada Buddhism, Brahmanism, Hinduism, and cultural beliefs in ghosts, deities and spirits. The community is regarded as a place where the changing dynamics of cultural beliefs exist.

Such cultural beliefs reveal that the community residents have realized the value of 'giving'. Such finding was consistent with Hauerwas and Pinches (1997), asserting that it is better to give than to receive. That is, it does not only mean giving objects but also includes giving respect to others with no insult with caring and nurturing attitudes. To value something as living things has resulted from the cultural nurturing of gentle minds, being considerate towards others, not oneself. This cultural process has helped to develop ethics and morality in individual minds in later generations unconsciously. It also marks the process of cultural groupings, which is consistent with Wongthet (1987) and Kroeber (1948, as cited in Buaphian, 1995).

\subsection{Beliefs in Tuad: Roles of Folklore in the Community of Thungwang}

The notions in Four Functions of Folklore (Bascom, 1965) posit that beliefs can be retained in society to exercise their social roles as cultural knowledge. Such beliefs validate and justify rituals and also are a pedagogic device in a society where folklore is being used in order to keep social norms. They also provide a way to escape pressure through entertainment (Bascom, 1965). In his major article "Four Functions of Folklore", Bascom (1965) illustrated that folklore could perform four major functions as follows: (1) it provides entertainment and pleasure (literally enjoyment or an escape from reality), (2) it validates and justifies the significance of rituals, which helps complete culture, (3) it is a means of education, serving as a pedagogical device to reinforce socialization, and (4) it helps maintain social norms.

From the abovementioned, it could be said that the major role of folklore is to maintain the stability of culture. Through the lens of the notions in "Four Functions of Folklore" by Bascom (1965), we could examine the roles of rituals towards community members in different aspects as follows:

1) Rituals can serve as and be hailed as moral support among community members;

2) Rituals can serve to control social behaviors;

3) Rituals can bind community members to preserve unity;

4) Rituals can be a pedagogical tool to educate and guide members about the significance of life;

5) Rituals can serve as a tool to reveal the identity of the community;

6) Rituals can help ease pressure but bring pleasure to community members.

We found that the beliefs in Tuad play another role, which is to promote the unity of the community through cooperation in making merit; that is to allow all residents, either the elders or children, to entertain themselves with daily activities, meeting, conversing and helping each other in doing something. These result in greater understanding, enjoyment, and appreciation among the community members. Sometimes, a festive event is held to provide entertainment, being the time for making effort together with enjoyment. This cooperation extends to a wider scope of support on other occasions when they face difficulties. Telling a story or folktale is actually a way that local residents convey their beliefs from generation to generation through storytelling. In this case, they 
convey the beliefs in the supernatural and sacredness of Tuad Yaita Thabo, which justifies and develops their faith and helps to develop living conditions and social organization (Phongphaibun, 1997). This also justifies a social custom of living together despite religious diversity in the community where the members can live peacefully without any physical, verbal or mental disrespect through the belief in an object such as a sculpture. This sculpture plays a symbolic role which helps make the processes of conveying the beliefs successful. Moreover, it validates the traditional rituals as a central social element in order for the local residents to express their warm relationship to each other, signifying a respect to their ancestors and the elders who have brought them up with care and affection through loving attitudes, being aware of appreciation in return. The rich help the poor, which reflects the deep roots of Thai culture. It can be asserted that such folk ways can be seen as social norms that community members use for appropriate values and behaviors in certain social circumstances (Satsanguan, 1991). As a result, community members can live and be engaged in social interactions properly because these folk ways can serve as social norms to govern their interactions. As such, it maintains Thai culture. To put it simply, this generosity of the rich will raise their own social status as 'givers'. They will be given more respect and be more recognized by others, which benefits their social power base in the community.

The processes of creating such beliefs as that of Tuad Yaita Thabo in Thungwang Subdistrict are actually in line with the traditional view of universe which sees invisible bodies as abstract entities embodying spiritual values. Through these processes, the community members are able to learn the meaning of true happiness by the means of 'giving'. They can make merit, undergo self-denial, and have respect for others. This is in line with the Social Exchange Theory which is central to the political system together with control of social power (Mauss, 1967). The theory is rooted in economics and other disciplines, positing that human choices of decision in a certain circumstance are made on the basis of greatest benefits and lowest costs. These great benefits have economic aspects as well as in psychological ones, such as reconciliation within groups, as well as respect, admiration, and reputation in society.

In his book, The Gift: Forms and Functions of Exchange in Archaic Societies, Mauss (1967) explained that exchanges undertaken with commitment have socially shared rewards or benefits. In terms of structure, forms of exchanging in society imply thoughts at a deeper level than the simple exchange of things or gifts. That is bound by obligations. Exchanging systems have three types of obligations. The first type is the obligation to give. To give is the heart of political systems as well as authority and social control. The second one is the obligation to receive. If someone gives a gift to us, then to refuse the gift indicates weakness, resistance, opposition, and pre-surrender, that is to have an obligation to return. The obligation to return shows friendship and social intercourse. It can be said that to exchange or to give is to underscore the interpersonal or intergroup relationship; it can bind human life ways. This is in line with Sunyavivat (2007) who asserts that exchanging can be undertaken in the form of trading goods, gathering community members to help a member do something (e.g., at harvest time), counter trading, and taking an oath. The items being used for exchange not only include objects or money, but also involve ideas, knowledge, virtue, or protection. All of which are considered as exchange items. The exchange theory also contributes to human living in terms of forming social groups since human beings could not live alone. To form a social group is to exchange friendship with each other, resulting in promoting close relationships through providing assistance, having sympathy for those who suffer, and empowering the community through building public awareness, devoting oneself to the public, developing community unity, and peace. All of these are consistent with the concept of 'to give'.

As mentioned above, the notion of the exchange theory is not only applied to business activities. It also contributes to human living with the 'each other' concept, empowering social groups to settle down, and to form a community and society.

According to a Buddhist principle, 'Dana' means generosity or giving physical objects, however, in terms of the abstract, this term refers to forgiveness, having respect, giving support and assistance, respecting life, obeying parents and elders, having respect for teachers, showing generosity to relatives, friends, and priests. To give and to show generosity as well as caring for subordinates is a moral principle for Buddhists, which could blend all abstract ideas of 'giving' together more firmly and obviously than the concrete one. This is in line with the cultural phenomena in the community mentioned above, which aims to cultivate moral issues in younger generations through sacred objects. The local residents then can acquire and absorb the cultural view of caring for others more than for oneself, appreciation of others, wanting to repay, and sharing through votive offerings, making offerings, having respect, forgiving those who apologize, and treating a sacred object as a living thing through kinship relationship. In this case, Tuad is a term to call a great-grandmother. The cultural strategy of naming aims to gradually cultivate a positive attitude of co-living with others happily with community members.

The roles of Tuad Yaita Thabo have continued in the community firmly. The residents in Sai Khrob Village in 
Thungwang Subdistrict, Songkhla Province, have preserved traditional community events to show their unity. Their folktales which have been narrated can help discipline the members of the community and communities nearby following different religions to learn how to live with others on the grounds of respect for others, both physically and spiritually.

Moreover, the community residents have determined to believe in Tuad Yaita Thabo. This can be observed by the annual increase in the number of participants in the festive event of Tuad Yaita Thabo. The underlying belief system justifies and reinforces this cultural practice when the community members face difficulties beyond human control (Ramitanonta, 1984). This affirms that such beliefs are a symbolic spiritual center to provide moral support for those devotees.

The beliefs in sacredness in the community have been preserved up to the present. In spite of the fact that such beliefs might have dissolved at some point, they were recreated and maintained to meet the community needs deliberately. For instance, the folktales could be evidence to indicate sacredness by supporting one's respect for visible objects, justifying a ritual to provide spiritual values and meaningfulness to devotees. Such cultural practices have supported the existence of Tuad. Despite global changes, human life patterns which are immersed with suffering and happiness truly persist. If there is a way to ease difficulties, provide moral support, and keep life balance, it will be held as a spiritual supporting element for human beings. Therefore, beliefs cannot be judged as right or wrong and good or bad when judged by the scientific principles of knowledge.

\section{Conclusion}

A belief was developed by ancestors through their wisdom and wit. They perceived that a remote community lacking social and economic development, an area where city laws and customs were not fully enforced and needed to be regulated by creating powerful entities. These could give support to members and any insulting remark to these entities was prohibited. Therefore, certain beliefs were produced in order to monitor and control behavior as well as keeping community members in order and living peacefully together. The beliefs in sacred objects have developed the sense of humbleness among members. Moreover, such beliefs cultivate the attitude of asking when there is a need, not through robbery, nor by being aggressive, rude, or violent, and also by developing the sense of 'giving' more than 'receiving'. That is, they cultivate the attitude of loving and caring for others as we would wish others to treat us. Typically, cultural heritage normally embraces the beliefs that members have faith in their communities. Any sacred entity is endorsed in one's community; community members normally help promote its existence and create a long history with great holy power in order to believe that such a sacred entity could give either blessings if worshiped or punishment if disrespected. This process helps attach mystical power to that sacred entity. This cultural trick is regarded as a favorable one as a Thai proverb says 'A ghost puppet is displayed to deceive men'. This helps to monitor and control individuals to prevent misconduct. The authors assert that such beliefs in Tuad which still remain have an important role of creating a strong bond among the community members of Thungwang Subdistrict. This might be considered as absurd in the eyes of modern rationalists who uphold scientific methods. However, if this is seen as a bond of holding individuals with virtues by using the power of faith, we can see that the belief in Tuad is a wise cultural strategy by a group of people to cultivate a happy and peaceful life among their community members. At least, their lives then can be secured by employing faith in Tuad Yaita Thabo as a device to bind community members together.

It can be concluded that the role of Tuad Yaita Thabo in the community lies in the following three important elements. The first element is the power of folk tales which have been passed down from generation to generation in terms of its sacredness. Conventionally, folk tales might be condensed from time to time by subsequent generations who do not give much detail. Narrators might adjust the details of the folk tales to correspond to current cultural beliefs, traditions, and social patterns held by both narrators and listeners. This reflects the underlying social preferences and contexts which help to shape the society as desired by the social members (Thalang, 2005). The second element entails the power of symbolism, which includes worshiped objects and revered entities. The symbolism helps to shape the abstract concepts into concrete ones, to become tangible through symbolic representations in order to be venerated and worshipped. The last element is the power of rituals as sacred activities according to community beliefs. These involve making offerings, paying respect, and performing traditional rituals. When all of the three elements function firmly in the community and the society, then the life of such beliefs can survive indefinitely.

\section{References}

Bascom, W. (1965). Four functions of folklore. In A. Dundes (Ed.), The study of folklore (pp. 279-298). New Jersey: Prentice-Hall. 
Brown, R. A. R. (1965). Structure and function in primitive society. New York: Free Press.

Buaphian, J. (1995). Beliefs and rituals about religious shrines of residents in Na San District, Surat Thani Province (Unpublished master's thesis). Rinakharinwirot University, Songkhla, Thailand.

Geertz, C. (1966). Religion as a Cultural System. In M. Banton (Ed.), Anthropology approaches to the study of religion. London: Tavistock Publication Limited.

Hauerwas, S., \& Pinches, C. R. (1997). Christians among the virtues. Indiana: University of Notre Dame Press.

Howells, W. W. (1962). The heathens, primitive man and his religions. Garden City: Doubleday.

Kroeber, A. L. (1948). Influence. Anthropology, 603-604. New York: Wenner-Gren Foundation for Anthropological Research.

Malinowski, B. (1954). Myth in Primitive Psychology. Magic science and religion, 57-59. New York: Doubleday Anchor Books.

Mauss, M. (1967). The Gif: Forms and functions of exchange in archaic societies. New York: W.W. Norton and Company.

Misap, K. (1993). Dream. Bangkok, Thailand: Samit.

Phongphaibun, S. (1997). Structures and dynamics of Thai southern culture in relation to development. Bangkok, Thailand: Thailand Research Fund.

Ramitanonta, C. (1984). Master's ghost. Chiangmai, Thailand: Chiangmai University.

Satsanguan, N. (1991). Social organization. Society and culture, 63. Bangkok, Thailand: Chulalongkorn University.

Songmuang, S., \& Thiangdham, C. (1999). Songkhla: Province. Encyclopedia of Thai southern culture, 15, 7585. Bangkok, Thailand: Foundation of Thai Culture Encyclopedia, Siam Commercial Bank.

Srisuchat, T. (1999). Ancient stoves in Pa-o community. Encyclopedia of Thai southern culture, 6, 2754-2762. Bangkok, Thailand: Foundation of Thai Culture Encyclopedia, Siam Commercial Bank.

Sunyavivat, S. (2007). Theories in sociology: Overview and basic applications (12th ed.). Bangkok, Thailand: Chulalongkorn University.

Thalang, S. N. (2005). Theories of folk tales: Methodology for analysing legends and folk tales. Bangkok, Thailand: Chulalongkorn University.

Tylor, E. B. (1958). Primitive culture. New York: Harper Torchbooks.

Wikipedia. (2011). Dream. Retrieved April 22, 2011, from http://th.wikipedia.org

Wongthet, P. (1987). Beliefs and belief systems in Thai society. Thai art, plays and local performances: Unit 1-8, 50-65. Nonthaburi, Thailand: Sukhothai Thammathirat Open University.

\section{Appendix}

\section{Interviewers}

Chainui, W. (2011, January 4). Interviewed at 114, Village No. 8, Thungwang Subdistrict, Muang Songkhla District, Songkhla Province.

Chaithong, P. (2011, August 1). Interviewed at 13, Village No. 8, Thungwang Subdistrict, Muang Songkhla District, Songkhla Province.

Changthong, P. (August 1, 2011). Interviewed at 17/4, Village No. 8, Thungwang Subdistrict, Muang Songkhla District, Songkhla Province.

Nokkaew, C. (2011, March 6). Interviewed at 120/2, Village No. 8, Thungwang Subdistrict, Muang Songkhla District, Songkhla Province.

Petcharat, C. (2011, August 1). Interviewed at 120, Village No. 8, Thungwang Subdistrict, Muang Songkhla District, Songkhla Province.

Rattaya, T. (2011, January 4). Interviewed at 30, Village No. 8, Thungwang Subdistrict, Muang Songkhla District, Songkhla Province.

Sriyom, N. (2011, March 6). Interviewed at 60/2, Village No. 8, Thungwang Subdistrict, Muang Songkhla District, Songkhla Province.

\section{Copyrights}

Copyright for this article is retained by the author(s), with first publication rights granted to the journal.

This is an open-access article distributed under the terms and conditions of the Creative Commons Attribution license (http://creativecommons.org/licenses/by/3.0/). 